\title{
Improvement of Efficiency and Electrical Energy Consumption of AB74 Degradation Process Using a Novel Cylindrical Batch Photochemical Reactor
}

\author{
MOHAMMAD EBRAHIM OLYA ${ }^{* 1}$, YASER AKHI $^{1}$ and REZA MARANDI ${ }^{2}$ \\ 'Department of Applied Chemistry, Faculty of Chemistry, \\ North Tehran Branch, Islamic Azad University, Tehran, Iran. \\ ${ }^{2}$ Department of Environmental Engineering, Faculty of Engineering, \\ North Tehran Branch, Islamic Azad University, Tehran, Iran. \\ ${ }^{*}$ Corresponding author E-mail: akhi_yaser@yahoo.com \\ http://dx.doi.org/10.13005/ojc/320303
}

(Received: May 07, 2016; Accepted: June 19, 2016)

\begin{abstract}
Optimization of electric energy consumption in degradation of Indigo Carmine based on a new cylindrical batch suspension photocatalytic reactor designing concerning the main engineering parameters such as mixing, reaction kinetic, mass transfer, catalyst illumination, and inherent potential of contaminant was done. The most degradation efficiency was observed within in air flow rate 1.2L. $\mathrm{min}^{-1}$, initial hydrogen peroxide concentration $0.0294 \mathrm{~mol}^{-\mathrm{L}^{-1}}, \mathrm{pH}$ between $2-3$, initial dye concentration $10 \mathrm{mg} \cdot \mathrm{L}^{-1}$, and initial $\mathrm{TiO}_{2}$ dose $2 \mathrm{~g} \cdot \mathrm{L}^{-1}$. Applying optimum condition eventuated $76.09 \% \mathrm{TOC}$ reduction after 60 min reaction time. The results show that designed reactor is extremely affective in reduction of operational cost.
\end{abstract}

Keywords: Advanced oxidation processes, Acid Blue 74, $\mathrm{TiO}_{2}$ nanoparticles, photochemical reactor.

\section{INTRODUCTION}

Synthetic dyes are used extensively in different industries such as textile, cosmetics, food, pharmaceutical, tanning, paper, etc. It has been estimated that $1-20 \%$ of the world dye production is released into the environment during synthesis, processing, and finishing, which causes serious problems to the environment, because dyes are generally non-biodegradable, toxic, potentially carcinogenic, and non-aesthetic pollutants that reduce light penetration in the contaminated waters and threat aquatic life practically ${ }^{1-5}$. Therefore, dye removal of wastewaters using non-biological methods is necessary since as mentioned before, most of these compounds are non-biodegradable, and less than 10 azo dyes are purged with biological methods ${ }^{6}$. Other techniques such as adsorption, ion 
exchange, filtration, and coagulation only succeeded in transfering of dyes from water to another phase and they will require the secondary purification of solid wastes, regeneration of adsorbent or filteration that make the process more costly $y^{3,7-9}$.

Advanced Oxidation Processes (AOPs) have been shown as a promising alternative techniques. These processes generally involve generation and use of powerful but relatively nonselective transient oxidizing species, primarily the hydroxyl radical $\left({ }^{\circ} \mathrm{OH}\right)$ that would even mineralize refractory pollutants $\mathrm{s}^{8,10,11}$. Different types of AOPs, such as $\mathrm{UV} / \mathrm{H}_{2} \mathrm{O}_{2}, \mathrm{UV} / \mathrm{TiO}_{2}$, and $\mathrm{UV} / \mathrm{H}_{2} \mathrm{O}_{2} / \mathrm{TiO}_{2}$ were successfully used to treat various pollutants in water ${ }^{12-17}$. In these processes, the powerful hydroxyl radical with a high oxidation potential $(2.8 \mathrm{eV})$, is degradation agent. It can oxidize variety of organic compounds and non-selectively attack to molecules that is an advantage for oxidizing agent in wastewater treatment. The ability of performance under ambient conditions, complete mineralization of organic carbon into $\mathrm{CO}_{2}$ are some other considerable advantages of AOPs. Moreover, $\mathrm{TiO}_{2}$ photocatalyst is widely available, biological inert, inexpensive, non-toxic, and shows a relatively high chemical stability ${ }^{1,8,10,18,19}$.

In spite of mentioned advantages some important commitments including drastic limitation in the depth of UV light penetration because of strong adsorption on catalyst and contaminants, the necessity of uniform radiation of catalyst surface, recombination of photogenerated electron-holes on the catalyst surface, signalize the significance of reactor designing ${ }^{20-22}$. In the present paper an optimization on amount of electrical energy consumption for treatment of Indigo Carmine as a specific contaminant concerning suitable reactor designing and effect of key operating parameters such as initial air flow rate $(F)$, initial hydrogen peroxide concentration $\left(\left[\mathrm{H}_{2} \mathrm{O}_{2}\right]_{0}\right)$, initial solution $\mathrm{pH}$, initial dye concentration $\left([\mathrm{AB} 74]_{0}\right)$, and initial $\mathrm{TiO}_{2}$ dose has been done.

\section{EXPERIMENTAL}

\section{Reagents}

$5,5^{\prime}$ - Indigotin disulfonic acid disodium salt (85\%), commercially named C.I. Acid Blue 74 or
AB74, was obtained from Merck and used without purification. The physicochemical characteristics of the mentioned dye are given in Table 1. Hydrogen peroxide $(30 \% \mathrm{~W} / \mathrm{W}), \mathrm{H}_{2} \mathrm{SO}_{4}(98 \%)$, and $\mathrm{NaOH}$ (>98\%) were also obtained from Merck. Titanium dioxide was supplied by Plasmachem (P25).

\section{Photocatalyst characterization}

To characterize crystalline phase and the size of $\mathrm{TiO}_{2}$ particles, XRD analysis was used with Scherrer equation. The experiment was carried out with a STOE transmission diffractometer. Interpretation of spectrum shows that photocatalyst is composed of anatase and rutile structures with $80: 20$ ratios, and the average size of particles was estimated to be $21.5 \mathrm{~nm}$ (Fig. 1). Fig. 2 shows the TEM bright-field image of Plasmachem $\mathrm{TiO} 2$ particles that confirms the aforementioned average size.

\section{Photocatalytic degradation procedure}

In each experiment $1 \mathrm{~L}$ of the dye solution was prepared using distillated water with the desired initial dye concentration. The desired $\mathrm{pH}$ was adjusted through adding diluted aqueous solution of $\mathrm{H}_{2} \mathrm{SO}_{4}$ or $\mathrm{NaOH}$ (different concentration of $\mathrm{H}_{2} \mathrm{SO}_{4}$ or $\mathrm{NaOH}$ was prepared for preventing changes in volume). Dye solution was poured into the photochemical reactor and the required amount of $\mathrm{H}_{2} \mathrm{O}_{2}$ and $\mathrm{TiO}_{2}$ was added. During irradiation, samples were collected at regular intervals and were centrifuged at 4000 rpm to remove any suspended solid before analysis. Degradation process was studied by monitoring the UV-Vis absorption spectra at $\lambda_{\max }(610 \mathrm{~nm})$ and TOC analysis results. Degradation percentages were calculated using following formulas:

$$
\operatorname{Dec} \%=\left(A_{0(610)}-A_{(610)} / A_{0(610)}\right) \times 100
$$

where $A_{0(610)}$ and $A_{(610)}$ are the absorbency at $\mathrm{t}=0$ and desired time respectively.

$$
\operatorname{Deg} \%=\left(\mathrm{TOC}_{0}-\mathrm{TOC} / \mathrm{TOC}_{0}\right) \times 100
$$

where $\mathrm{TOC}_{0}$ and $\mathrm{TOC}$ are the total organic carbon at $\mathrm{t}=0$ and desired time recpectively. 


\section{RESULT AND DISCUSSION}

\section{Reactor designing}

Photocatalytic reactor designing is faced to more complications than traditional reacor. Besides catalyst installation, mixig, reaction kinetic, mass transfer, another engineering parameter namely catalyst illumination becomes appear. An excellent interaction between light absorption, transport processes, reaction kinetic leads to strong coupling of physicochemical phenomena which is the major problem in designing of photocatalytic reactor. The amount of catalyst that can be activated determines the water treatment capacity of the reactor, so that the illumination parameter has the most importance ${ }^{20-22}$. In order to achievement of highest catalyst surface exposure to illumination a suspension photocatalytic reactor was concerned. By placement of illumination source (Osram 15W low-pressure mercury lamp, maximum emission at $254.7 \mathrm{~nm}$ ) in the center of the vessel most utilization was achieved. Concerning to the illumination source place that causes some limitations in agitation agent, air was injected into the solution through two tubes as the agitator (Fig. 3).

Moreover existent oxygen in air would be changed to Singlet molecular oxygen by irradiation of Indigo Carmine that has a key role in wastewater treatment ${ }^{23}$. The photosensitization process for this species is as follows:

$$
\begin{aligned}
& \operatorname{Sen}\left(S_{0}\right) \stackrel{\text { hu }}{\rightarrow} \operatorname{Sen}\left(S_{1}\right) \\
& \operatorname{Sen}\left(S_{1}\right) \stackrel{\text { Fluorescence }}{\longrightarrow} \operatorname{Sen}\left(S_{0}\right) \\
& \operatorname{Sen}\left(S_{1}\right) \stackrel{\text { IC }}{\rightarrow} \operatorname{Sen}\left(S_{0}\right)
\end{aligned}
$$$$
\operatorname{Sen}\left(\mathrm{S}_{1}\right) \stackrel{\mathrm{ISC}}{\rightarrow} \operatorname{Sen}\left(\mathrm{T}_{1}\right)
$$

$$
\operatorname{Sen}\left(\mathrm{T}_{1}\right)+{ }^{3} \mathrm{O}_{2} \stackrel{\text { Type II, energy transfer }}{\longrightarrow} \operatorname{Sen}\left(\mathrm{S}_{0}\right)+{ }^{1} \mathrm{O}_{2}
$$

$$
\operatorname{Sen}\left(\mathrm{T}_{1}\right)+{ }^{3} \mathrm{O}_{2} \stackrel{\text { Type I, electron transfer }}{\longrightarrow} \operatorname{Sen}^{*+}\left(\mathrm{S}_{0}\right)+\mathrm{O}_{2}^{\cdot-}
$$

$$
\operatorname{Sen}\left(\mathrm{S}_{0}\right)+{ }^{1} \mathrm{O}_{2} \stackrel{\text { Physical deactivation }}{\longrightarrow} \operatorname{Sen}\left(\mathrm{S}_{0}\right)+{ }^{3} \mathrm{O}_{2}
$$

$$
\operatorname{Sen}\left(\mathrm{T}_{1}\right) \stackrel{\text { Phosphorescence }}{\longrightarrow} \operatorname{Sen}\left(\mathrm{S}_{0}\right)
$$

Type 22 mechanism includes ${ }^{1} \mathrm{O}_{2}$ production through energy transfer between $\mathrm{T} 1$ photosensitizer state and ground state ${ }^{3} \mathrm{O}_{2}$ (Eq. 7). Type ${ }^{2}$ mechanism includes abstraction of hydrogen atom or electron transfer between the excited photosensitizer and a substrate which finally produces oxygen radical. One example from reaction type ${ }^{2}$ is making superoxide due to transfer of electron from one excited sensitizer to ${ }^{3} \mathrm{O}_{2}$ (Eq. 8). Energy transfer from the excited Indigo Carmine to ${ }^{3} \mathrm{O}_{2}$ is equal to $\mathrm{E}_{\mathrm{T}}=27-32 \mathrm{Kcal} \cdot \mathrm{mol}^{-1}$. Also, considering the fact that energy difference between triple-ground and first excited singlet state of oxygen is $22.5 \mathrm{kcal}^{\mathrm{mol}}{ }^{-1}$, so Indigo Carmine in the excited triplet state can react with ${ }^{3} \mathrm{O}_{2}$ to produce ${ }^{1} \mathrm{O}_{2}$ in accordance with Eq. 7. The amount of ${ }^{1} \mathrm{O}_{2}$ produced by Indigo Carmine is affected by certain parameters like sensitizer and oxygen concentration, temperature, and irradiation time. Quantum yield of ${ }^{1} \mathrm{O}_{2}$ production for Indigo Carmine is estimated to be about $0.3-0.6^{24}$. Two methods are suggested for deactivation of ${ }^{1} \mathrm{O}_{2}$ :

a)

$$
{ }^{1} \mathrm{O}_{2}+\mathrm{A} \stackrel{\mathrm{k}_{\mathrm{p}}}{\rightarrow}{ }^{3} \mathrm{O}_{2}+\mathrm{A}
$$
product is produced (physical quenching).

b)

$$
{ }^{1} \mathrm{O}_{2}+\mathrm{A} \stackrel{\mathrm{k}_{\mathrm{c}}}{\rightarrow} \mathrm{P}
$$

In the second method quencher reacts with the singlet oxygen and new product is produced (chemical quenching).

Researches have shown that excited oxygen in singlet state is about $1 \mathrm{~V}$ more oxidizing than oxygen with basic energy and is much more electrophilic. It can immediately react with unsaturated $\mathrm{C}-\mathrm{C}$ bonds and neutral nucleophiles like 
sulphides, amines and anions. While excited triplet molecules can act as efficient sensitizers of singlet oxygen, in most of the cases, they themselves can act as efficient quenchers of this species. This process could lead to photobleaching and photodegradation. Photobleaching is most seen in degradation of dyes with singlet oxygen ${ }^{23}$. Therefore using this inherent specific of Indigo Carmine could improve reaction kinetic and consequently decrease the reaction time and electrical energy consumption.

\section{The effect of initial air flow}

In order to evaluate the influence of $\mathrm{UV}, \mathrm{H}_{2} \mathrm{O}_{2}$, Aeration, and $\mathrm{H}_{2} \mathrm{O}_{2}$ /Aeration on the degradation process preliminary experiments were carried out before the main experiments. Results show that the influence of these parameters on the dye decolorization was negligible. Therefore, combination of UV irradiation and oxidation agent is obligatory to start the decolorization reaction.

As results shown in Fig. 4, decolorization percentage after $100 \mathrm{~min}$ is equal to $92.3 \%, 95.1 \%$, $96.9 \%, 100 \%$ and $100 \%$ in $0.3,0.6,0.9,1.2$ and 1.5 L. $\mathrm{min}^{-1}$ air flow rates respectively, so we can choose 1.2 L. $\mathrm{min}^{-1}$ as the optimum air flow rate. This is because of an increase in system turbulence, gas-liquid interfacial and mass transfer coefficient, each of which supply sufficient oxygen for oxidation process ${ }^{7}$.

LC-MS and ${ }^{1} \mathrm{HNMR}$ studies have shown that Indigo Carmine will be destroyed and converted to Isatin (Eq. 13).

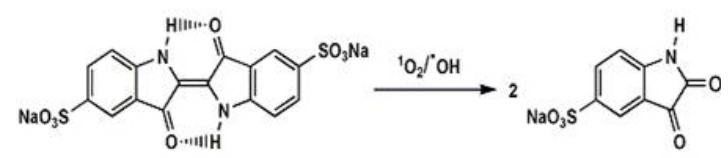

Self-decay rate constant $\left(\mathrm{K}_{\mathrm{d}}\right)$ is equal to $(1.9 \pm 0.3) \times 10^{4} \mathrm{~s}^{-1}$. As already mentioned, single oxygen causes oxidative degradation of indigo carmine through reaction with central $\mathrm{C}=\mathrm{C}$ bond. Also, oxidation may be done through reaction with superoxides produced in type ${ }^{2}$ mechanism (Eq. 14) $)^{3,24,25}$.

$\mathrm{RH}+\mathrm{O}_{2}^{*-} \rightarrow$ Products

\section{The effect of initial hydrogen peroxide concentration}

The attack of photon on $\mathrm{H}_{2} \mathrm{O}_{2}$ and formation of hydroxyl radical (Eq. 15) is the main step in UV/ Aeration $/ \mathrm{H}_{2} \mathrm{O}_{2}$ process ${ }^{25-27}$.

$\mathrm{H}_{2} \mathrm{O}_{2}+\mathrm{hv} \rightarrow 2^{\circ} \mathrm{OH}$

Increase of initial hydrogen peroxide concentration to the optimum value due to an increase in the formation of hydroxyl radicals leads to a dramatic rise in degradation percentage of $A B 74$. But it should be noted that hydroxyl and superoxide radicals can react or recombine according to the following reactions:

$$
\mathrm{H}_{2} \mathrm{O}_{2}+\mathrm{OH} \rightarrow \mathrm{HO}_{2}^{*}+\mathrm{H}_{2} \mathrm{O}
$$

$\cdot \mathrm{OH}+{ }^{\circ} \mathrm{OH} \rightarrow \mathrm{H}_{2} \mathrm{O}_{2}$

$$
\cdot \mathrm{OH}+\mathrm{HO}_{2}^{\cdot} \rightarrow \mathrm{H}_{2} \mathrm{O}+\mathrm{O}_{2}
$$

$$
\mathrm{HO}_{2}^{*}+\mathrm{HO}_{2}^{*} \rightarrow \mathrm{H}_{2} \mathrm{O}_{2}+\mathrm{O}_{2}
$$

$$
\mathrm{HO}_{2}^{-}+\mathrm{O}_{2}^{--} \rightarrow \mathrm{HO}_{2}^{-}+\mathrm{O}_{2}
$$

${ }^{\circ} \mathrm{OH}+\mathrm{O}_{2}^{-} \rightarrow \mathrm{O}_{2}+\mathrm{OH}^{-}$

According to these reactions, hydroxyl radical assists in competition reactions instead of reaction with dye molecules and will be recombined or consumed consequently degradation rate will decrease, therefore defining appropriate amount of initial hydrogen peroxide concentration is an important step to avoid an excess amount of reagent ${ }^{28,29,30}$. Fig. 5 shows the optimum value of the relative hydrogen peroxide concentration, which is expressed as the mass ratio of the $\mathrm{H}_{2} \mathrm{O}_{2}$ concentration to that of the dye $(\mathrm{H})$, is 50 (molar ratio is about 685.5, $\left[\mathrm{H}_{2} \mathrm{O}_{2}\right]_{0}=0.0294$ mol. $\left.\mathrm{L}^{-1}\right)$. This value varies in different experimental conditions and reactors. For instance, the optimum $\mathrm{H}_{2} \mathrm{O}_{2} / \mathrm{AB} 74$ molar ratio in a batch reactor with a $15 \mathrm{~W}$ 
low-pressure mercury lamp was 5000, as reported by Galindo et $\mathrm{al}^{3}$ and 1000 in a semi batch reactor with a 15W UV lamp, as reported by Aleboyeh et $\mathrm{al}^{31}$. This ratio decreased to 685.5 in this investigation, a fact that reveals better operation of the designed photoreactor which can consequently reduce costs through reduction of consumed reagents and process time, in fact, lower energy consumption reduces costs.

\section{The effect of initial pH}

Industrial wastewaters have various $\mathrm{pH}$ values; therefore, degradation of $\mathrm{AB} 74$ in the range of $\mathrm{pH}=2-10$ was studied. The highest rate of degradation was observed at $\mathrm{pH}=2-3$. Further increase in $\mathrm{pH}$ up to 10 has a reverse effect on the degradation rate, as illustrated in Fig. 6 , increase in $\mathrm{pH}$ from 3 to 10 decreases decolorization percentage from $100 \%$ to $71.5 \%$. This is due to several factors:

First, in alkaline $\mathrm{pH}$ values, $\mathrm{H}_{2} \mathrm{O}_{2}$ will decompose more to $\mathrm{H}_{2} \mathrm{O}$ and $\mathrm{O}_{2}$ instead of ${ }^{\circ} \mathrm{OH}$, because the first-order self-decomposition constant of $\mathrm{H}_{2} \mathrm{O}_{2}$ (Eq. 22) at $\mathrm{pH} 7.0$ and 10.5 are $2.29 \times 10^{-2}$ and $7.40 \times 10^{-2} \mathrm{~min}^{-1}$, respectively, that is approximately 3.2 times at $\mathrm{pH}=10.5^{32}$.

Table 1: Physicochemical characteristics of treated dye

\begin{tabular}{llccccc}
\hline Dye & $\begin{array}{l}\text { Molecule } \\
\text { Formula }\end{array}$ & $\begin{array}{c}\text { C.I. } \\
\text { Number }\end{array}$ & $\begin{array}{c}\mathrm{Mw} \\
\left(\mathbf{g} \cdot \mathrm{mol}^{-1}\right)\end{array}$ & $\begin{array}{c}\lambda_{\max } \\
(\mathbf{n m})\end{array}$ & $\begin{array}{c}\varepsilon \times 10^{-3} \\
\left(\mathrm{~L} . \mathrm{mol}^{-1} \cdot \mathbf{c m}^{-1}\right)\end{array}$ & structure \\
\hline AB74 & $\mathrm{C}_{16} \mathrm{H}_{8} \mathrm{~N}_{2} \mathrm{Na}_{2} \mathrm{O}_{8} \mathrm{~S}_{2}$ & 73015 & 466.36 & 610 & & \\
\hline
\end{tabular}

Table 2: Processes electricity cost, $F=1.2$ L.min ${ }^{-1}$, [AB74] $=20 \mathrm{mg} \cdot \mathrm{L}^{-1}, \mathrm{H}=50,\left[\mathrm{TiO}_{2}\right]=2 \mathrm{~g} \cdot \mathrm{L}^{-1}, \mathrm{pH}=$ Natural, $\mathrm{T}=25^{\circ} \mathrm{C}$

\begin{tabular}{lccc}
\hline Process & $\mathbf{K}\left(\mathbf{m i n}^{-1}\right)$ & $\mathbf{E}_{\mathrm{E0}}\left(\mathbf{k W h \mathbf { m } ^ { - 3 }}\right.$ order $\left.^{-1}\right)$ & Cost \\
\hline UV/Aeration & 0.0247 & 23.32 & 233.2 \\
UV/Aeration $/ \mathrm{TiO}_{2}$ & 0.4472 & 1.288 & 12.88 \\
UV/Aeration $/ \mathrm{H}_{2} \mathrm{O}_{2} / \mathrm{TiO}_{2}$ & 2.256 & 0.255 & 2.55 \\
\hline
\end{tabular}

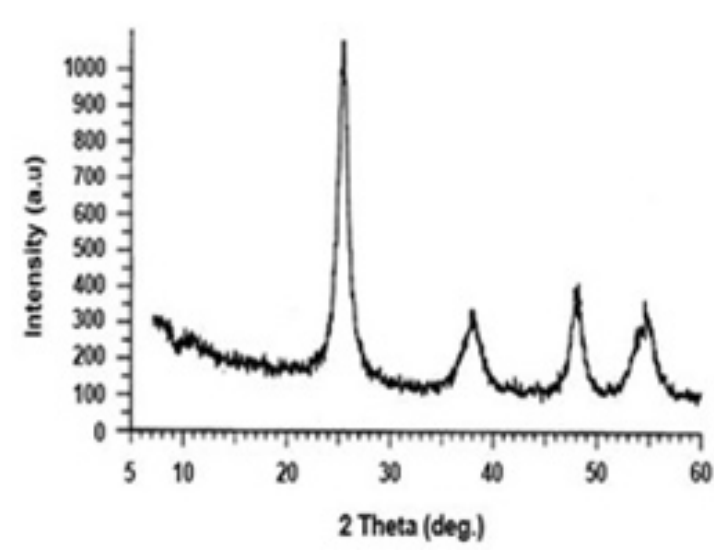

Fig. 1: XRD diffractogram of TiO2

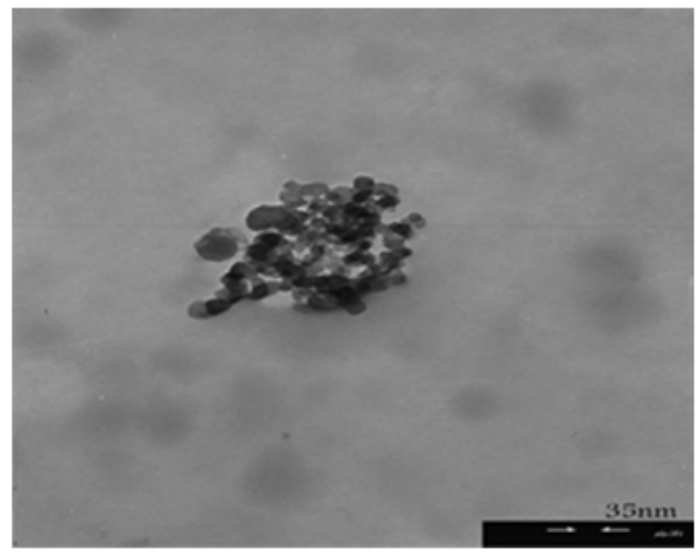

Fig. 2: TEM bright-field image of Plasmachem $\mathrm{TiO}_{2}$ particles 


$$
2 \mathrm{H}_{2} \mathrm{O}_{2} \rightarrow 2 \mathrm{H}_{2} \mathrm{O}+\mathrm{O}_{2}
$$

Second, in alkaline $\mathrm{pH}$ values, hydrogen peroxide and hydroxyl radicals concentration decrease (Eqs. 23-25), because hydroperoxy anion concentration (conjugate base of $\mathrm{H}_{2} \mathrm{O}_{2}$ ) increases at these $\mathrm{pHs}$ (Eq. 26), reacts with hydrogen peroxide and hydroxyl radicals consequently reduces the rate of dye degradation.

$\mathrm{HO}_{2}^{-}+\mathrm{H}_{2} \mathrm{O}_{2} \rightarrow \mathrm{H}_{2} \mathrm{O}+\mathrm{O}_{2}+\mathrm{OH}^{-}$

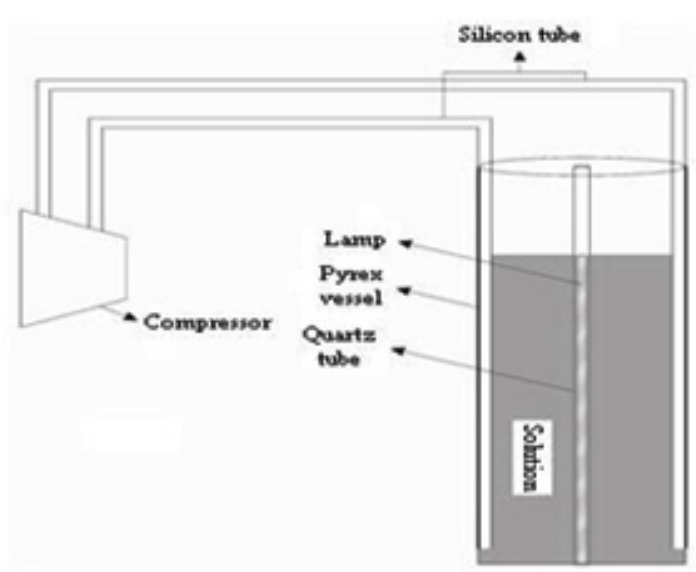

Fig. 3: Photoreactor

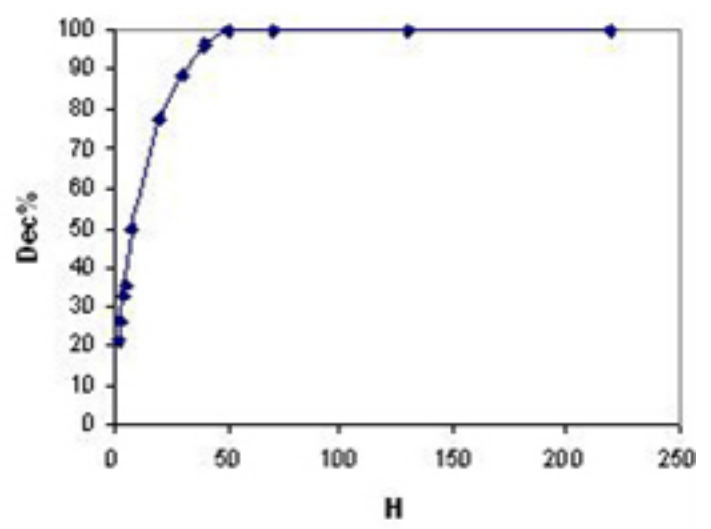

Fig. 5: The effect of initial hydrogen peroxide concentration on decolirozation percentage, $\mathrm{F}=1.2 \mathrm{~L} \cdot \mathrm{min}^{-1},[\mathrm{AB74}]=20 \mathrm{mg} \cdot \mathrm{L}\left\{{ }^{1}, \mathrm{pH}=\right.$ Natural, $t=90 s, T=25^{\circ} \mathrm{C}$ $\cdot \mathrm{OH}+\mathrm{HO}_{2}^{-} \rightarrow \mathrm{H}_{2} \mathrm{O}+\mathrm{O}_{2}^{-}$

${ }^{\circ} \mathrm{OH}+\mathrm{HO}_{2}^{-} \rightarrow \mathrm{HO}_{2}^{\circ}+\mathrm{OH}^{-}$

$\mathrm{H}_{2} \mathrm{O}_{2} \rightarrow \mathrm{HO}_{2}^{-}+\mathrm{H}^{+} \quad \mathrm{pk}_{\mathrm{a}}=11.6$

Third, the labile $\mathrm{H}$ atom in AB74 molecule is carried with $\mathrm{N}$ atom which is converted to the deprotonated form (conjugated base) in alkaline $\mathrm{pH}$ values. Degradation of this deprotonated form is less

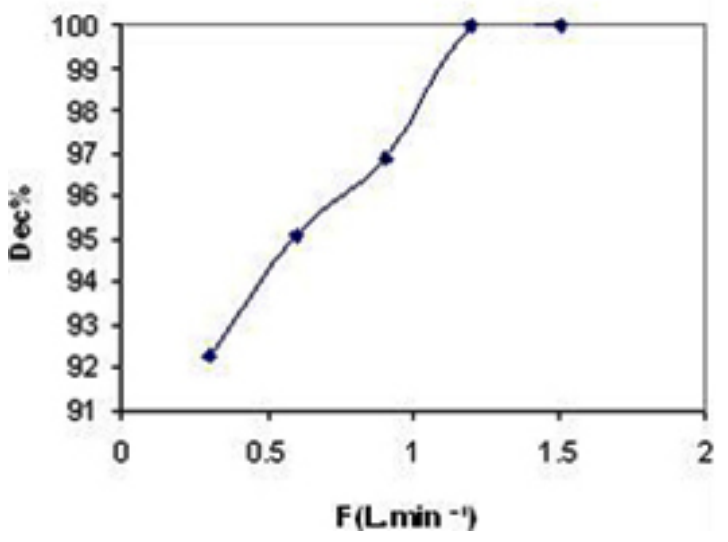

Fig. 4: Effect of $F$ on decolorization percentage, $[A B 74]=20 \mathrm{mg} \cdot \mathrm{L}\left\{{ }^{1}, \mathrm{pH}=\right.$ Natural, $\mathrm{t}=\mathbf{1 0 0} \mathrm{min}$, $\mathrm{T}=25^{\circ} \mathrm{C}$

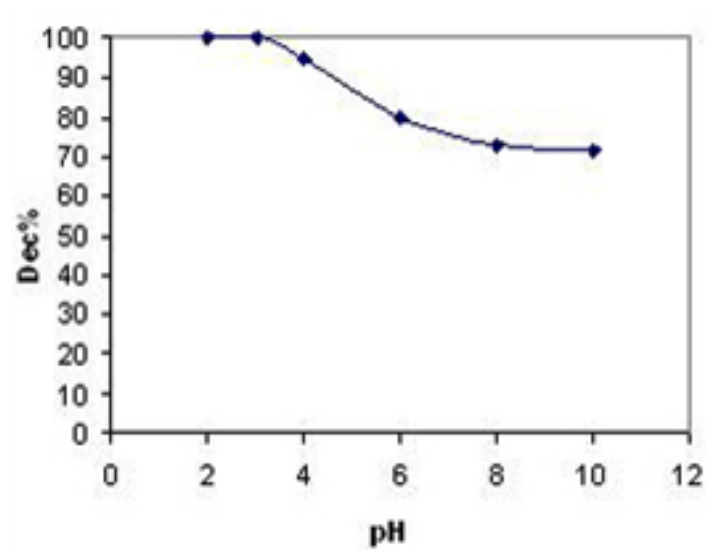

Fig. 6: The Effect of Initial pH on decolirozation percentage, $F=1.2{\mathrm{~L} . \mathrm{min}^{-1}}^{-1}$, [AB74] $=20 \mathrm{mg} . \mathrm{L}\left\{{ }^{1}\right.$, $\mathrm{H}=50, \mathrm{t}=60 \mathrm{~s}, \mathrm{~T}=25^{\circ} \mathrm{C}$. 


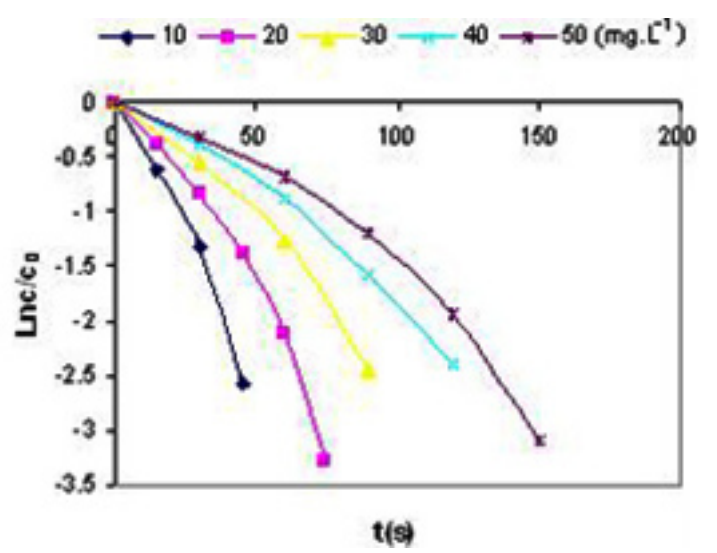

Fig. 7: Pseudo-first order decay curve at different $[A B 74]$ in UV/Aeration $/ \mathrm{H}_{2} \mathrm{O}_{2}$ process,

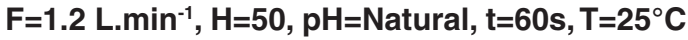

because hydroxyl radicals mostly oxidize organic

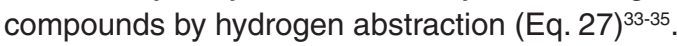

$$
\mathrm{RH}+{ }^{\circ} \mathrm{OH} \rightarrow \mathrm{R}^{*}+\mathrm{H}_{2} \mathrm{O}
$$

\section{The effect of initial dye concentration}

By increasing the initial dye concentration, $\mathrm{k}$ values and consequently degradation rate decreases (Fig. 7). Initial k values for dye solutions with 10, 20, 30,40 and $50 \mathrm{mg} \cdot \mathrm{L}^{-1}$ concentrations are 0.0523 , $0.0376,0.0246,0.0182$ and $0.0173\left(\mathrm{~s}^{-1}\right)$, respectively. This refers to the molar absorption coefficient of AB74 at 254nm that is nearly thousandfold of $\mathrm{H}_{2} \mathrm{O}_{2}$ $\left(18.7 \times 10^{3}\right.$ versus 18.61 L. mol-1. $\left.\mathrm{cm}^{-1}\right)$. Therefore, increase in dye concentration acts like an inner filter and the solution becomes impermeable to UV radiation and since $\mathrm{H}_{2} \mathrm{O}_{2}$ absorbs smaller fraction of UV light, fewer hydroxyl radicals are produced ${ }^{3}$.

\section{The effect of initial $\mathrm{TiO}_{2}$ dose}

Absorption of a photon with adequate energy, equal to or more than band-gap energy of the $\mathrm{TiO}_{2}(3.2 \mathrm{eV})$, initiates the process (Eq. 28). Consequently, an electron is promoted from the valance to the conduction band of the semiconductor, resulting in generation of a free electron and a positive hole. The photogenerated holes can oxidize the dye or react with $\mathrm{OH}^{-}$or $\mathrm{H}_{2} \mathrm{O}$ and oxidize them into ${ }^{\circ} \mathrm{OH}$. The photogenerated electrons can reduce the dye or react with electron acceptors like $\mathrm{O}_{2}$

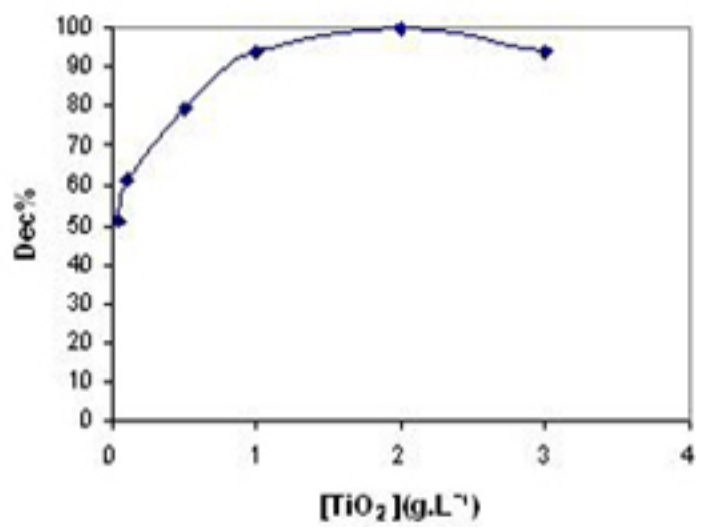

Fig. 8: The effect of initial $\mathrm{TiO}_{2}$ dose on decolorization percentage, $\mathrm{F}=1.2 \mathrm{~L}_{\mathrm{min}}{ }^{-1}$, [AB74] = $20 \mathrm{mg} . \mathrm{L}\left\{{ }^{1}, \mathrm{pH}=\right.$ Natural, $\mathrm{t}=9 \mathrm{~min}$, $\mathrm{T}=25^{\circ} \mathrm{C}$

(reducing it to superoxide radical anion $\left(\mathrm{O}_{2}^{-*}\right)$ ) or

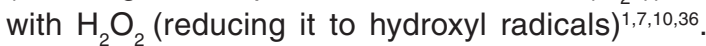
Recombination of photogenerated electron-holes is a serious problem in the use of photocatalysts, which is the main reason of energy dissipation and reduction of the quantum yield ${ }^{1,10,39,37}$. It has been demonstrated, providing the proper amount of oxygen is an important factor in the process that prevents recombination of photogenerated electronholes $^{7,37}$. The appropriate design of reactor in this research provides sufficient amount of oxygen for scavenging photogenerated electrons and preventing energy dissipation.

$$
\mathrm{TiO}_{2}+\mathrm{hv}(\mathrm{UV}) \rightarrow \mathrm{TiO}_{2}\left(\mathrm{e}_{\mathrm{CB}}^{-}+\mathrm{h}_{\mathrm{VB}}^{+}\right)
$$

Influence of catalyst amount on degradation efficiency was studied, as results in Fig. 8 show, after 9 minutes of irradiation, decolorization percentages are $51.1 \%, 61.2 \%, 79.8 \%, 94 \%, 100 \%$ and $93.9 \%$ at initial $\mathrm{TiO}_{2}$ amounts of $0.05,0.1,0.5,1,2$ and $3 \mathrm{~g} . \mathrm{L}^{-1}$ respectively. Therefore, an increase in initial $\mathrm{TiO}_{2}$ amount up to the optimum value $\left(2 \mathrm{~g} . \mathrm{L}^{-1}\right)$ leads to higher degradation rate due to increase in the number of active sites on the surface of photocatalyst and consequently an increase in hydroxyl and superoxide radicals. But, if this amount exceeds the optimum value, it can retard dye degradation because suspension will be impermeable toward 
UV radiation and will prevent illumination. Moreover, agglomeration of $\mathrm{TiO}_{2}$ particles masks part of the active sites ${ }^{7,36,38-40}$.

Comparison of the UV/Aeration, UV/Aeration/ $\mathrm{H}_{2} \mathrm{O}_{2}$, UV/Aeration/TiO ${ }_{2}$, and UV/Aeration $/ \mathrm{H}_{2} \mathrm{O}_{2}$ I $\mathrm{TiO}_{2}$ processes

Through comparing decolorization rates at the optimum conditions of each AOP, it was found that decolorization rates are 1.5, 1.5, 9, and $100 \mathrm{~min}$ in UV/Aeration/ $\mathrm{H}_{2} \mathrm{O}_{2} / \mathrm{TiO}_{2}$, UV/Aeration/ $\mathrm{H}_{2} \mathrm{O}_{2}, \mathrm{UV} /$ Aeration/ $/ \mathrm{TiO}_{2}$, and UV/Aeratio processes respectively. As results show decolorization rate is equal in two first processes surprisingly, but TOC results show a significance difference between them so that $76.09 \%, 65.22 \%, 55.43 \%, 7.47 \%$ TOC reduction were obtained after $60 \mathrm{~min}$ in each process. Mineralization rate variation is due to an increase in concentration of hydroxyl radicals in UV/Aeration $/ \mathrm{H}_{2} \mathrm{O}_{2} / \mathrm{TiO}_{2}$ process according to Eqs. 29-32.

$\mathrm{H}_{2} \mathrm{O}_{2}+\mathrm{O}_{2}^{--} \rightarrow{ }^{\circ} \mathrm{OH}+\mathrm{O}_{2}+\mathrm{OH}^{-}$

$\mathrm{TiO}_{2}\left(\mathrm{~h}_{\mathrm{VB}}^{+}\right)+\mathrm{H}_{2} \mathrm{O} \rightarrow \mathrm{TiO}_{2}+\mathrm{H}^{+}+{ }^{\circ} \mathrm{OH}$

$\mathrm{TiO}_{2}\left(\mathrm{~h}_{\mathrm{VB}}^{+}\right)+\mathrm{OH}^{-} \rightarrow \mathrm{TiO}_{2}+{ }^{\circ} \mathrm{OH}$

$\mathrm{TiO}_{2}\left(\mathrm{e}_{\mathrm{CB}}^{-}\right)+\mathrm{H}_{2} \mathrm{O}_{2} \rightarrow \mathrm{TiO}_{2}+{ }^{\circ} \mathrm{OH}+\mathrm{OH}^{-}$

\section{Economic computations}

Recently, International Union of Pure and Applied Chemistry (IUPAC) provided a method for computing the amount of electrical energy consumption in advanced oxidation processes. Regarding pseudo first order reactions, the parameter of electrical energy per order $\left(E_{E_{0}}\right)$ is defined as the necessary electrical energy in terms of $\mathrm{kWh}$ to reduce $90 \%$ of pollutant concentration in $1 \mathrm{~m}^{3}$ of the contaminated water. This parameter is calculated according to the following equations:

$$
E_{E_{0}}=(P \times t \times 1000) /\left(V \times 60 \times \log \left(C_{i} / C_{f}\right)\right)
$$

$\ln \left(\mathrm{C}_{\mathrm{i}} / \mathrm{C}_{\mathrm{f}}\right)=\mathrm{kt}$

where $P$ is the rated power $(\mathrm{kW})$ of the AOP system, $t$ is the irradiation time ( $\mathrm{min}), \mathrm{V}$ is the volume of wastewater in the reactor $(\mathrm{L}), \mathrm{C}_{\mathrm{i}}$ is the initial concentration of pollutant, $\mathrm{C}_{\mathrm{f}}$ is the final concentration of pollutant and $\mathrm{k}$ is the pseudo first order rate constant $\left(\mathrm{min}^{-1}\right)$. Using the above two equations we can reconstruct $E_{E_{0}}$ as follows ${ }^{41}$ :

$$
E_{E_{0}}=(38.4 \times P) /(V \times k)
$$

With the use of the defined parameters, if the price of electricity for every kWh is $10 \phi$, we can set the table 2 for AB74 degradation.

\section{CONCLUSION}

Many important parameters are effective in selection of a wastewater treatment technology including economic issues, environmental regulations, final quality of the purged wastewater, operational conditions (maintenance, control and safety) and the ability to update equipment. Although all these parameters are important, but as usual, the economic parameter is take priority. Since destruction of organic pollutant in water is a process which consumes electrical energy and this energy is considered as the main part of operational cost, so estimating the amount of energy consumption in the process can give us valuable information. During this work a precise calculation and optimization of electric energy consumption base on contaminant properties, process type, and other engineering parameters were done. Results confirmed extreme influence of studied parameters on operational cost. 


\section{REFERENCES}

1. Konstantinou, I.K.; Albanis, T.A.; Appl. Catal. B: Environ. 2004, 49, 1-14.

2. Sun, J.; Wang, X.; Sun, J.; Sun, R.; Sun, S.; Qiao, L.; J. Mol. Catal. A: Chem. 2006, 260, 241-246.

3. Galindo, C.; Jacques, P.; Kalt, A.; J. Photochem. Photobiol. A: Chem. 2001, 141, 47-56.

4. Saikia, J.; Das, G.; J. Environ. Chem. Eng. 2014, 2, 1165-1173.

5. Bansal, P.; Sud, D.; Desalination. 2011, 267, 244-249.

6. Forgacs, E.; Cserhati, T.; Oros, G.; Environ. Int. 2004, 30, 953-971.

7. Chakrabarti, S.; Dutta, B.K.; J. Hazard. Mater. 2004, B112, 269-278.

8. Andreozzi, R.; Caprio, V.; Insola, A.; Marotta, R.; Catal. Today. 1999, 53, 51-59.

9. Gutpa, V. K.; Jain, R.; Agarwal, S.; Shirvastava, M.; Colloids Surf., 2011, A378, 22-26.

10. Topuduti, K.; Tay, S.; Monschein, E.; Advanced photochemical oxidation processes, U.S.Environmental Protection Agency Publication, (1998).

11. Autin, O.; Hart, J.; Jarvis, P.; MacAdam, J.; Parsons, S. A.; Jefferson, B.; Wat. Res. 2013, 47, 2041-2049.

12. Slokar, Y.M.; Marchal, A.M.L.; Dyes Pigm. 1998, 37, 335-356.

13. Tanaka, K.; Padermpole, K.; Hisanaga, T.; Wat. Res. 2000, 34, 327-333.

14. Baran, W.; Makowski, A.; Wardas, W.; Dyes Pigm. 2008, 76, 226-230.

15. Guillard, C.; Disdier, J.; Herrmann, J.M.; Lehaut, C.; Chopin, T.; Malato, S.; Blanco, J.; Catal. Today. 1999, 54, 217-228.

16. Yang, H.; Li, G.; An, T.; Gao, Y.; Fu, J.; Catal. Today. 2010, 153, 200-207.

17. Rizzo, L.; Selcuk, H.; Nikolaou, A. D.; Pagona, S. M.; Belgiorno, V.; Desalin. Water Treat. 2014, 52, 1414-1421.

18. Vohra, M.S.; Davis, A.P.; Wat. Res. 2000, 34, 952-964.

19. Oturan, M. A.; Aaron, J. J.; Crit. Rev. Environ. Sci. Technol. 2014, 44, 2577-2641.

20. Mukherjee, P.S.; Ray, A.K.; Chem. Eng. Technol. 1999, 22, 253-260.
21. Ray, A.K.; Chem. Eng. Sci. 1999, 54, 31133125.

22. Periyathamby, U.; Ray, A.K.; Chem. Eng. Technol. 1999, 22, 881-888.

23. DeROsa, M.C.; Crutchley, R.J.; Coord. Chem. Rev. 2002, 233-234, 351-371.

24. Gandra, N.; Frank, A.T.; Gendre, O.L.; Sawwan, N.; Aebisher, D.; Liebman, J.F.; Houk, K.N.; Greer. A.; Gao, R.; Tetrahedron. 2006, 62, 10771-10776.

25. Crittenden, J.C.; Hu, S.; Hand, D.W.; Green, S.A.; Wat. Res. 1999, 33, 2315-2328.

26. El-Dein, A.M.; Libra, J.A.; Wiesmann, U.; Chemosphere. 2003, 52, 1069-1077.

27. Stefan, M.; Hoy, A.; Bolton, J.; Environ. Sci. Technol. 1996, 30, 2382-2390.

28. Aleboyeh, A.; Aleboyeh, H.; Moussa, Y.; Dyes Pigm. 2003, 57, 67-75.

29. Muruganandham, M.; Swaminathan, M.; Dyes Pigm. 2004, 62, 269-275.

30. Chang, M.W.; Chung, C.C.; Chern, J.M.; Chen, T.S.; Chem. Eng. Sci. 2010, 65, 135140.

31. Aleboyeh, A.; Aleboyeh, H.; Moussa, Y.; Environ. Chem. Lett. 2003, 1, 161- 164.

32. Chu, W.; Chemosphere. 2001, 44, 935-941.

33. Aleboyeh, A.; Moussa, Y.; Aleboyeh, H.; Dyes Pigm. 2005, 66, 129-134.

34. Beltran, F.J.; Gonzalez, M.; Gonzalez, J.F.; Wat. Res. 1997, 31, 2405-14.

35. Galindo, C.; Kalt, A.; Dyes Pigm. 1998, 40, 27-35.

36. Elmolla, E. S.; Chaudhuri, M.; Desalination. 2010, 252, 46-52.

37. Yamazaki, S.; Matsunaga, S.; Hori, K.; Wat. Res. 2001, 35, 1022-028.

38. Huang, M.; Xu, C.; Wu, Z.; Huang, Y.; Lin, J.; Wu, J.; Dyes Pigm. 2008, 77, 327-334.

39. Olya, M. E.; Pirkarimi, A.; Sep. Purif. Technol. 2013, 118, 557-566.

40. Gutpa, V. K.; Jain, R.; Mittal, A.; Saleh, T. A.; Nayak, A.; Agarwal, S.; Sikarwar, S.; Mater. Sci. Eng. 2012, C32, 12-17.

41. Daneshvar, N.; Aleboyeh, A.; Khataee, A.R.; Chemosphere. 2005, 59, 761-767. 